\title{
SCHOOL VIOLENCE IN DIVERSITY PERSPECTIVE: EVIDENCE FROM TEACHING AND LEARNING INTERNATIONAL SURVEY 2018
}

\author{
Onwubuya Gift Chinemerem ${ }^{\mathrm{i}}$ \\ Teacher Education, Faculty of Education, \\ Shanghai Normal University, \\ No. 100 Guilin Road, Shanghai, 200234, \\ P. R. of China
}

\begin{abstract}
:
Violence is a widespread global problem in society and schools in particular; education stakeholders are charged with the urgency of diminishing violent behavior and delinquency in schools. This research was conducted using the cross-national principal data set from the 2018 Teaching and Learning International Survey (TALIS) administered by the Organization for Economic and Co-operation and Development (OECD). The study examined the relationship between school violence and professional development in leadership, it also explored how multicultural diversity policies and practices, school multicultural environments relate to violence in schools. Country fixed effect estimate was conducted to explore the relationship between school leadership, multicultural environment, multicultural policies and practices, and school violence in 47 countries. Results indicate that school leadership is adversely related to school violence, multicultural policies and practices were interestingly found to affect school violence positively. The results added nuance to previous studies that school leadership can play a cogent role in school violence, schools should invest in creating policies and practices that are core in self-affirmation and inclusive of all students.
\end{abstract}

Keywords: school violence, professional leadership development, multiculturalism, multicultural policies, and practices

\section{Introduction}

Violence refers to the intentional use of power or actual force or threat against oneself, others, or a group or community. It either causes or is highly likely to cause injury, death, and all kinds of harm to victims (World Health Organization [WHO], 2002). Violence is a widespread global problem in society and schools in particular. More than one billion school children experience physical, sexual, or psychological violence or neglect (Horan, 2002). Over the last decade, bullying, indiscipline, fighting are top problems faced by

'Correspondence: email onwubuyagift@gmail.com 
public schools (Lunenburg, 2010b). Cornell and Mayer (2010), and Fong et al. (2008) specifically identified school violence as a persistent global problem, as an indicator of an unsafe environment for learning presents an urgency and challenge for school leaders. Supported by Bosworth et al. (2018), studies focused on school discipline, intervention, safety, and academic success has found leadership as an essential factor in the school environment. Principals not only manage school activities, but they also implement policies, models and promote behaviors that foster a conducive environment (Chavis \& Blakely, 2010; Leff, 2014; Leinhardt \& Willert, 2002; Lunenburg \& Irby, 2005; Lunenburg, 2010a; Melvin, 2011). Supporting the above fact, a study in leadership conducted in Australia by De Nobile et al. (2016) found out that leadership is very critical in whole school behavior management. Although Principal leadership play a crucial role in the establishment and maintenance of effective school management indispensable for the effectual reduction of violence (Bourne et al., 2015), it is vital that leadership development be reflected in policies and actions implemented.

In the $21^{\text {st }}$ century, schools have become more diverse, reflecting the cultural diversity in society. Diversity and multiculturalism are concepts of variation among learners in an educational setting. They encompass students' linguistic origin, cultural, ethnic, and social differences (Hellblom-Thibblin, 2018). These social differences include (but are not confined to) culture, differences in origin and ethnic identity, gender, socioeconomic class, sexual identity, religion, and language (Harm \& Marianne, 2000). Some previous studies examined the relationship between the social difference that exists in the classrooms and violence which may lead to conflicts. For instance, Stevenson et al. (2002) mentioned that in junior schools, more than the white race, blacks are more likely to be victims of violence. While conflicts and misunderstandings can occur due to obliviousness of the exiting social rules in others' cultures, approaches to handling school violence must consider the important role that culture and race may play in the school environment (DeFour, 2005). Furthermore, Caldwell et al. (2004) researched violent behavior in African American youth, examined the connection between racial discrimination and cultural identity. They posit that violent actions in young adults both male and female are predicted by prejudice.

The inconsistent argument on the relationship between multiculturalism and violence gave insight into the current study. Le and Johansen (2011) researched a city in northern California using an ethnically diverse sample of 324 junior school children having an average age of 12.5 years, ranging from 11 to 15 years and $50 \%$ female, the study reported a negative correlation between school diversity and interpersonal violence. In another study, Juvonen et al. (2006) found out that in a racially and ethnically diverse school environment, ethnic minorities suffer less harm and discrimination. They contend that this occurred due to parity of power where there is no single predominant class. On the contrary, Vervoort et al. (2008) reported that in a heterogeneous school environment, ethnic minorities participated in more bullying and victimization, they believe that in ethnic group competition theory, the abundance of multiple ethnic groups 
creates a social threat and the urge to instill group preeminence. Thus, examining the influence of multiculturalism can be valuable in studying violence.

Globally, the status of schools is experiencing rapid change due to the influx of migrates and demographic differences. Taking advantage of this diversity as ethnic minorities become part of the school population are of great significance in promoting positive reform (Earley \& Mosakowski, 2000; Stevens et al., 2008) through fostering both individual and group belonging. In educational contexts, policies targeted at diversity, explicitly dealing with cultural differences, encompass different policy methods that either pay attention to, ignore, or reject cultural pluralism (Guimond et al., 2014). These policy approaches include multiculturalism and colorblindness, assimilation (Celeste et al., 2019; Guimond et al., 2014; Plaut et al., 2018; Stevens et al., 2008). In the multiculturalism approach, school multicultural policies and practices recognize and value diversity (Rosenthal \& Levy, 2010) by affirming students' differences and distinct cultural backgrounds (Derks et al., 2007; Dovidio et al., 2009). Schools adopt educational practices like "cultural diversity day" where students exhibit and learn each other's heritage to promote intercultural tolerance and understanding (Verkuyten \& Thijs, 2013). On the other hand, colorblind approaches ignore differences; it attaches less importance to uniqueness, stresses individualism equal treatments regardless of differences in identity (Rosenthal \& Levy, 2010; Stevens et al., 2008), while assimilation endorses more of majority culture (Celeste et al., 2019).

The literature on diversity policy approaches also produced inconsistent views of the effects of policies and practices, and this creates a need for further research. Some researchers supported the benefit of multicultural policies to promote a persistent organizational climate of acceptance and tolerance (Stevens et al., 2008). Hornsey and Hogg (2000) argue the benefits of valuing diversity, people become generous and tolerant towards other cultures when their identity is represented. Students benefit from diversity when they feel inclusive in the existing multicultural practice (Meeussen et al., 2014; Stevens et al., 2008). However, some researchers affirm that Schools, through policies and practices, suppress and reinforce inequalities in ways they approach diversity (Banks, 2015; Stevens et al., 2008). In schools consisting of both minorities and non-minorities, non-minorities develop negative views of multicultural policies, they become noncompliant and resistant to multicultural policies and initiatives, leading to the failure of policy objectives (Brief et al., 2005; Thomas, 2008). Consequently, Plaut et al. (2007) state that valuing cultural diversity excludes non-minorities, threatening unity, feeling excluded or alienated (Stevens et al., 2008). As underlined by Hornsey and Hogg (2000), a threat to identity provokes behaviors and may cause conflict within large groups having different subgroups. When minorities or non-minorities encounter identity threats from multicultural policies (Verkuyten, 2005), they display identity protection actions, varying from the intolerance of external groups to resisting co-existing and conflicts. In line with this, some researchers criticize multiculturalism in preserving ethnic boundaries and identities to promote separatism and division (Brewer, 1993; Sears et al., 1999) cited in (Hornsey \& Hogg, 2000). Individuals become ethnocentric, devaluing 
and downgrading other ethnic groups (Taylor et al., 1987), but when they perceive equal treatment, they feel less prejudice (Roebroeck and Guimond (2015). Students' perceptions of equal treatment keep a good school atmosphere, lessen threats to identity. For students to feel equal treatment in school, school leaders need to build inclusive school culture. School leaders act as an important decision-making authority (Penlington, Kington, \& Day, 2008). As leaders in the school, principals hold a vital position in guiding changes and maintaining a good school atmosphere. Principal leadership by producing a thriving core of leaders among teachers, parents, and community members drives most changes in the school (Bryk, 2010). To prevent the occurrence or escalation of student deviant behavior, Principals as leaders manage students' behaviors by developing practices and policies, rules, and regulations (Kinsler, 2013) that are expected to improve a collegiality, safe and caring environment. Nooruddin and Baig (2014) carried out a study in secondary school in Karachi, Pakistan on teachers and students, the study found that school leadership influences student behaviors positively by selecting policies and practices that permeate school cultures. This study hypothesizes that professional development in leadership enables leaders while paying attention to instructional effectiveness would adopt policies and programs that diminish school violence. However, not much research has focused on exploring school leadership with policies and practices targeted at multicultural school environments and school violence. The limitation of the literature offers the opportunity for current empirical research investigating the effect of school leadership training in a multicultural school environment on violence. First, many researchers on the verge of solving this global problem have taken few directions; a lot of interest was focused on the effects and perception of violence by either students or teachers. In the knowledge of the researcher, there are no studies that examine principal professional development in leadership and if multicultural programs in schools could have an impact on school violence. Secondly, most research on violence examines the incidence, types, and danger factors adopting qualitative methods for descriptive statistics. This research aims to fill the literature gap by examining professional development in leadership and how school multicultural environments and policies and practices are linked with school violence. It is imperative to conduct additional studies to investigate the selected variable of the study using extensive data to generate more objective results, which could be discussed aiming at solutions. In developing and expanding upon the current literature on School violence, our study aims to examine the following research questions.

1) What is the relationship between school violence and school professional development in leadership?

2) Does multicultural diversity policies and practices, school multicultural environment link to violence in school?

With this objective, our research creates intuition for educational leaders and policymakers to uphold and initiate policies while evaluating programs and activities for a positive and safe school climate. 


\section{Method}

\subsection{Data and Sample}

To examine the research questions, the author utilized TALIS 2018 cross-national data of 48 participating countries and economies. TALIS survey focuses on professional and pedagogical practices at both at school and teacher level (OECD, 2019a). TALIS 2018 data at the school level was on school leadership, school climates and also involved policies and research concerns connected to innovation equity and diversity(OECD, 2019a). This study used the core data of 47 out of 48 participating countries in TALIS 2018, excluding Iceland data as requested by the country (OECD, 2019b). TALIS asked School principals to account for whether violence has occurred in their schools and what level and if they have received professional leadership training within the last 12 months. The core target population in TALIS is the International Standard Classification of Education \{ISCED\} level 2 (lower secondary) teachers and school principals. Students enter ISCED level 2 at the age of 10-13age, programs under ISCED level 2 may be called in different ways if there are program that cover both ISCED level 3 and 4- Secondary school, Junior secondary school, Middle school, Junior high school. If there are programs that spans level 1 and 2 -Basic school or Elementary education is mostly used, but for the purpose of international comparability "lower secondary education" is generally used. In this study, we used the institutional data from 200 lower secondary schools in each country. To address the issue of missing values of 903 in the variables used for this study which represents $0.977 \%$, the values were replaced with series mean.

\subsection{Measures}

The variables used in this study involve the original variables synthesized by TALIS 2018. They include four variables: the dependent variable, the independent variable, covariates, and other study variables.

\subsection{Dependent Variable}

The dependent variable is School violence, synthesized into a composite variable using seven items of five Likert scale (from 1 to 5, 1= Never=1, 2= less than monthly, 3=monthly, $4=$ weekly, 5=daily). The researcher synthesized a composite variable using the seven items (e.g., how often the following does occur) a) vandalism and theft. b) Intimating or bullying among students (or order forms of verbal abuse). c) Physical injuries caused by violence among students. d) Intimidation of verbal abuse of teachers or staff. e) Use or possession of drugs and/or alcohol. f) A student or parent/guardian reports hurtful information on the internet about students. g) A student or parent guardian reports unwanted electronic contact among students (e.g. texts, e-mails, online). To maximize the variability in the data, the principal component analysis was employed with varimax rotation. Findings from the PCA show that the eigenvalue of the first component was 3.68 and the second was 1.07 which accounted for $67 \%$ of the variance. The Kaiser-MeyerOlkin measure of sampling adequacy test result of $0.84 \%$ indicates that factor analysis is 
useful with the data and further confirmed by the results of Bartlett's test of sphericity with a $1 \%$ statistical significance.

\subsection{Independent Variable}

The key independent variable includes a binary variable, professional development training in leadership. TALIS 2018 asked school principals if they have participated in leadership training in the last 12 months.

\subsection{Covariates}

For the potential cofounders in the study, based on previous reviews on the school-level analysis (Garet et al., 2001), The researcher accounted for the cofounders involving gender, educational background, experiences as a principal in current school, and experience as a school principal in total, school location, school type (public or private school), employment status (full or part-time working status). All these variables come from the principal survey as we did not use data from the teacher level. See appendix A for a summary of the variables.

This study used other two variables to answer the second research question, a composite variable of policy and practices in multicultural education. The principal component analysis (PCA) results show that the eigenvalue of the first component was 2.31 and the second was 1.36, which accounted for $67 \%$ of the variance. The Kaiser-MeyerOlkin measure of sampling adequacy test result of $0.65 \%$ indicates that factor analysis is useful with the data and further confirmed by the results of Bartlett's test of sphericity with a $1 \%$ statistical significance. The second variable is multicultural background in the schools, schools that identified for their ethnic and cultural pluralism.

\subsection{Empirical Model}

To establish the link between professional development in leadership (PDL) for principals and school violence (SV) as well as the effect of multicultural school environment and policies implemented aimed at diversity on school violence, country fixed effect model approach was employed for this study. The fixed-effect model assumes that differences across units can be captured as differences in the constant term. This eliminates the heterogeneous characteristics that have not been considered in the panel sample. Therefore, the following functional form gives the basic model estimated for this study;

$$
S V_{n m}=\alpha_{n}+\beta_{1} P D L_{n m}+\beta_{2} M C E_{n m}+\beta_{3} M P P_{n m}+\beta_{4} P C_{n m}+\beta_{5} S C_{n m}+\lambda_{C}+\varepsilon_{n m}(1)
$$

In equation (1), $S V_{o c}$ denotes the dependent variable school violence in school $n$ and country $m . P D L_{n m}$ represents the main independent variable whether a principal participated in professional development in leadership; $M C E_{n m}$ and $M P P_{n m}$ indicates whether a school is composed of students from different backgrounds and whether policies and practices are implemented to promote diversity respectively; other 
regressors include $P C_{n m}$ being a vector for principal's characteristics such as years of experience in present school and total, employment status, educational background; $S C_{n m}$ is also a vector of the school characteristics such as school's status(public or private), and school location; $\lambda_{C}$ signifies a country fixed effects; and $\varepsilon_{n m}$ connotes the random error term.

\section{Results}

Table 2 reports the results obtained from the correlation between the variables. For research question one, professional development in leadership has no significant effect on school violence (see Table 2). Multicultural policies and practices implemented contribute positively and significantly to school violence. In contrast, a Multicultural school environment is inversely linked with school violence, and the status of a school public or private also negatively influences school violence, with both variables statistically significant at $1 \%$. The location of schools contributes positively to school violence, and the result is also statistically significant at $1 \%$. The employment status of principals negatively and significantly influences school violence, while their experience in total and current school has no significant relationship with school violence. A highly statistically significant inverse relationship is identified between the educational level of principals and school violence. On the other hand, the gender of principals negatively affects school violence with a coefficient of -0.076 and a $1 \%$ level of significance.

Results from Table 3 shows that professional development in leadership has an inverse relationship with school violence (see Table 3). However, the negative relation between the two variables with a coefficient of -0.002 and a statistically not significant probability of 0.827 . It means that in the OECD countries analyzed for this study, professional development in leadership received by principals of lower secondary institutions potentially decreases school violence; however, this is not significant. Interestingly, for research question two, according to the results, policies, and practices implemented in relation to diversity are positively linked to school violence. These policies aimed at promoting diversity significantly contribute positively to school violence. Furthermore, a multicultural school environment has a negative effect on a coefficient of -0.121 on school violence and is statistically significant. It implies that a school environment with students of more than one culture or ethnic background significantly reduces school violence. Whether a school operates in the private sector or public has a statistically significant negative relationship (a coefficient of -0.271 ) with school violence. In terms of demography, a school location has a positive (with a coefficient of 0.047 and probability of 0.000 ) association with school violence in the OECD countries assessed in this study. This infers that a school's location in terms of being a rural area, town, or city contributes significantly to school violence, as shown in the results. The employment status of principals negatively affects school violence. It means that whether a principal is employed as full-time or part-time negatively influences school violence and is statistically significant. Also, the years of experience a principal 
acquired in total potentially declines school violence with a coefficient of -0.001 and statistically significant at $10 \%$, while the years of experience of principals in current school also significantly affect school violence at $1 \%$ significance and with a coefficient of -0.004. Finally, as reported from the fixed effect estimation, the level of education and gender of principals is positively associated with school violence 0.023 and 0.026 coefficients respectively at a $1 \%$ level of significance.

\section{Discussion}

\subsection{The Relationship between School Violence and School Professional Development in Leadership}

The study presents the cross-national analysis findings using data from TALIS 2018. The current study explored the relationship between professional development in leadership and school violence. Further, the researcher looked at the link between multicultural policies and practices, multicultural school environment, and school violence. Country fixed effect was used to control for the country-level heterogeneity and across-group actions (Allison, 2009). From the findings, professional development in leadership has a negative but statistically insignificant impact on school violence. Leff (2014) made similar findings in a quantitative study carried out in middle schools located in a large, urban district in south Florida. Employing the Pearson correlations and multiple linear regression models, the study reports that were no statistically significant relations between leadership styles and bullying or fighting. Henderson (2013) also found that principal leadership styles have no significant correlation with school violence. Given that in the results, school leadership is negatively related to school violence, but not statistically significant, school professional leadership development could consider providing more leadership training explicit on handling school conflict and violence to improve school climate. Supporting the findings of Bosworth et al. (2018) an exploratory study using longitudinal multilevel data of high schools that participated in a school safety grant, school leadership is a positive factor in achieving school climate change and significantly resulted in a decrease in bullying behaviors. Reduction in school delinquency and violence is one significant component of a positive school climate; principal with their leadership skills possesses an important position in the school to establish a positive school environment (Bellibaş, 2015; McGuigan \& Hoy, 2006).

The results also showed that school location is negatively associated with school violence; whether a school is located in a rural area, town or city increases school violence, this aligns with the findings of Crawford and Burns (2016). Additionally, the works of Henderson (2013) reported that cofounders variables such as school size, socio-economic status have a highly significant impact on school violence. These findings imply that school violence is more likely to be influenced by school features such as demographics. Thence, school professional leadership development could consider providing more leadership training explicit in handling school violence, as principals in this study only reported if they participated in leadership training in the last 12 months without details 
of the contents of the training, more studies are needed to look in professional development and training specifically in handling violence. Yet, from the extant literature review, this study is the first to examine the relationship between professional development in leadership, multicultural policies and practices, multicultural school environment, and school violence and providing cross-national evidence for it. By doing so, the present studies expand existing literature as mentioned by some researchers that more work is needed to be done on school violence (Debarbieux \& Cooke, 2007).

\subsection{Multicultural School Environment and School Violence}

By linking a multicultural school environment to school violence, the results of the study show that a multicultural school environment is inversely linked with school violence; schools that have a high multicultural environment experience reduced violence. These results are aligned with the findings of Le and Johansen (2011), using structural equation modeling with bootstrapping, a sample of 324 middle school youth from a city in northern California, the result shows a negative correlation between multiculturalism and interpersonal violence in school. These findings have implications related to coexistence in a diverse environment where there is a balance of power and not having one majority group (Juvonen et al., 2006). A defining aspect of multiculturalism is appreciating cultural diversity (Rattan \& Ambady, 2013; Rosenthal \& Levy, 2010) and it's essential educational values-cognitive, social, and emotional, for children to relate and interact with mates of different backgrounds, cultures, and race (Wells et al., 2016). A multicultural setting has a beneficial value to not only enhancing student learning but also increasing positive relationships among peers (Gurin et al., 2009). Another author echoed more reasons why schools should embrace diversity (Smith \& Schonfeld, 2000); students who attend schools with students of racially and culturally diverse have greater exposure and vast arrays of experience and ideas that potentially improve the education of all students. The findings suggest policies and implications for educational stakeholders on the beneficial values of having a diverse learning environment and how it may improve the peaceful relationships in the schools, improving the cultural competency of students and teachers to live in the increasingly diversified world of today.

\subsection{Multicultural Practice and Policies and School Violence}

Interestingly, the study results also indicated that multicultural policies and practices implemented in relation to diversity have a positive relationship to school violence. Possible explanations could be that programs related to diversity, for example, organizations and activities that encourage students' expression of ethnic and cultural identities like artistic groups, could lead to gang activities in the school, where members of an identified group try to establish social dominance over another group. As schools are made of both minority and non-minority, some policies and practices valuing cultural diversity may be threatening to non-minorities (Stevens et al., 2008), making them feel excluded or alienated (Plaut et al., 2018); in turn, they become resistant to multicultural 
policies and initiatives leading to the failure of policy objectives (Brief et al., 2005). When students perceive a threat to identity, this provokes behaviors and may cause conflict within large groups having different subgroups (Hornsey \& Hogg, 2000). Schools may invest in creating policies and practices that are core in self-affirmation and inclusive (Stevens et al., 2008) of all students, this would foster the benefits of multiculturalism and reducing conflicts among groups. This implies that policies should be formulated to benefit everyone as opposes to a single group. The foundation of developing policies and practices of all-inclusive is to center on the creation of high-quality interactions among students, such relationships that have a positive impact, encourage continuous learning, be flexible, have longevity (Stevens et al., 2008), making for smooth co-existence among members of the school. The study further implies that policies and activities that are implemented in school should be accompanied by effective leadership and proper supervision. School leaders should also make regular evaluations of policies and practices implemented in schools in accountability of their impacts on the school climate.

\subsection{Limitations and Future Research}

Although the findings of this study expanded the knowledge in providing significant insight into the relationship between professional leadership development, multicultural environment, school policies and practices in a diverse environment, and school violence using cross-sectional data. First, a longitudinal research design could explore the possible changes of school leadership, multicultural policies, and multiculturalism with other possible influencing factors. Second, future studies could consider student and teacher level variables to investigate the relationship between school professional leadership development, multicultural school environment, school policies and practices in a diverse environment, and school violence. Lastly, due to the nature of our data, the multicultural levels of schools in terms of the heterogeneous and homogeneous composition of the cultures were not placed into consideration. Further studies could consider using a homogeneous school population or heterogeneous school setting to explore the relationship between policies and practices in a diverse environment, school leadership specifically in handling violence, multicultural school environment, and school violence.

\section{Acknowledgement}

The author thanks Professor Chen Yongming, (Shanghai Normal University) for his endless guidance and discussions. The author also expresses appreciation to Nahai Gu (Shanghai Normal University) for his pearls of wisdom and intellectual assistance during the course of this research.

\section{Conflict of Interest Statement}

The author declares that there are no conflicts of interest. 


\begin{abstract}
About the Author
Onwubuya Gift Chinemerem is a doctorate student in the department of teacher education at Shanghai Normal University. Her research interests focus on multicultural education, teacher professional development with emphasis on diversity and leadership. She is interested in using research to improve and foster equity in education.
\end{abstract}

\title{
References
}

Allison, P. D. (2009). Fixed effects regression models. SAGE publications, Inc. https://www.doi.org/10.4135/9781412993869

Banks, J. A. (2015). Cultural diversity and education: Foundations, curriculum, and teaching. Routledge.

Bellibaş, M. Ş. (2015). Principals' and teachers' perceptions of efforts by principals to improve teaching and learning in Turkish middle schools. Educational Sciences: Theory E Practice, 15(6). https://doi.org/10.12738/estp.2016.1.0009

Bosworth, K., Garcia, R., Judkins, M., \& Saliba, M. (2018). The impact of leadership involvement in enhancing high school climate and reducing bullying: An exploratory study. Journal of school violence, 17(3), 354-366. https://doi.org/10.1080/15388220.2017.1376208

Bourne, P., Clarke-Christian, J., Sharpe-Pryce, C., Hudson-Davis, A., \& Francis, C. (2015). Strategies in dealing with violence in schools: Perceived effectiveness of conflict management strategies used by education leaders in reducing students' disagreements. Psychiatry, 18(2), 248. https://doi.org/10.4172/psychiatry.1000248

Brewer, D. J. (1993). Principals and student outcomes: Evidence from US high schools. Economics of Education Review, 12(4), 281-292. https://doi.org/10.1016/02727757(93)90062-1

Brief, A. P., Umphress, E. E., Dietz, J., Burrows, J. W., Butz, R. M., \& Scholten, L. (2005). Community Matters: Realistic Group Conflict Theory and the Impact of Diversity. Academy of Management Journal, 48(5), 830-844. https://doi.org/10.5465/amj.2005.18803925

Bryk, A. S. (2010). Organizing Schools for Improvement. Phi Delta Kappan, 91(7), 23-30. https://doi.org/10.1177/003172171009100705

Caldwell, C. H., Kohn-Wood, L. P., Schmeelk-Cone, K. H., Chavous, T. M., \& Zimmerman, M. A. (2004). Racial discrimination and racial identity as risk or protective factors for violent behaviors in African American young adults. American journal of community psychology, 33(1), 91-105. https://doi.org/10.1023/b:ajcp.0000014321.02367.dd

Celeste, L., Baysu, G., Phalet, K., Meeussen, L., \& Kende, J. (2019). Can School Diversity Policies Reduce Belonging and Achievement Gaps Between Minority and Majority Youth? Multiculturalism, Colorblindness, and Assimilationism Assessed. 


Personality and Social Psychology Bulletin, 45(11), 1603-1618.
https://doi.org/10.1177/0146167219838577

Chavis, B., \& Blakely, C. (2010). Crazy Like a Fox: One Principal's Triumph in the Inner City. Penguin.

Cornell, D. G., \& Mayer, M. J. (2010). Why do school order and safety matter? Educational Researcher, 39(1), 7-15. https://doi.org/10.3102/0013189x09357616

Crawford, C., \& Burns, R. (2016). Reducing school violence: Considering school characteristics and the impacts of law enforcement, school security, and environmental factors. Policing: An International Journal of Police Strategies $\mathcal{E}$ Management, 39(3), 455-477. https://doi.org/10.1108/PIJPSM-05-2016-0061

De Nobile, J., El Baba, M., \& London, T. (2016). School leadership practices that promote effective whole school behaviour management: a study of Australian primary schools. School Leadership $\mathcal{E}$ Management, 36(4), 419-434. https://doi.org/10.1080/13632434.2016.1247041

Debarbieux, E., \& Cooke, R. (2007). The international fight against school violence: Programs and routines. Urban Ed, the magazine of the Rossier School of Education, 3639.

DeFour, D. C. (2005). Gender and ethnicity issues in school violence Violence in Schools (pp. 85-99). Springer. https://doi.org/10.1007/0-387-28811-2 6

Derks, B., Van Laar, C., \& Ellemers, N. (2007). The Beneficial Effects of Social Identity Protection on the Performance Motivation of Members of Devalued Groups, Social Issues and Policy Review, 1(1), 217-256. https://doi.org/https://doi.org/10.1111/j.1751-2409.2007.00008.x

Dovidio, J. F., Gaertner, S. L., \& Saguy, T. (2009). Commonality and the Complexity of "We": Social Attitudes and Social Change. Personality and Social Psychology Review, 13(1), 3-20. https://doi.org/10.1177/1088868308326751

Earley, C. P., \& Mosakowski, E. (2000). Creating Hybrid Team Cultures: An Empirical Test of Transnational Team Functioning. Academy of Management Journal, 43(1), 2649. https://doi.org/10.5465/1556384

Fong, R. S., Vogel, B. L., \& Vogel, R. E. (2008). The correlates of school violence: An examination of factors linked to assaultive behavior in a rural middle school with a large migrant population. Journal of school violence, 7(3), 24-47. https://doi.org/10.1080/15388220801955521

Guimond, S., de la Sablonnière, R., \& Nugier, A. (2014). Living in a multicultural world: Intergroup ideologies and the societal context of intergroup relations. European $\begin{array}{llll}\text { Review of Social } & \text { Psychology, 25(1), }\end{array}$ https://doi.org/10.1080/10463283.2014.957578

Gurin, P., Dey, E., Hurtado, S., \& Gurin, G. (2009). Diversity and Higher Education: Theory and Impact on Educational Outcomes. Harvard Educational Review, 72(3), 330-367. https://doi.org/10.17763/haer.72.3.01151786u134n051

Harm, B., \& Marianne, A. (2000). The cycle of socialization. Readings for diversity and social justice, 15-21. 
Hellblom-Thibblin, T. (2018). Challenges and dilemmas-a conceptual approach to children's diversity in school. European journal of special needs education, 33(1), 1-15. https://doi.org/10.1080/08856257.2017.1297570

Henderson, J. H. (2013). A mixed methods study: Principals' perceived leadership styles and ability to lead during a school violence crisis. Indiana University of Pennsylvania.

Horan, J. J. (2002). Violence prevention: The development of Internet-delivered, experimentally-evaluated, psychological-education curricula. Journal of school violence, 1(4), 65-80. https://doi.org/10.1300/j202v01n04 05

Hornsey, M. J., \& Hogg, M. A. (2000). Assimilation and Diversity: An Integrative Model of Subgroup Relations. Personality and Social Psychology Review, 4(2), 143-156. https://doi.org/10.1207/S15327957PSPR0402 03

Juvonen, J., Nishina, A., \& Graham, S. (2006). Ethnic Diversity and Perceptions of Safety in Urban Middle Schools. Psychological Science, 17(5), 393-400. https://doi.org/10.1111/j.1467-9280.2006.01718.x

Kinsler, J. (2013). School discipline: A source or salve for the racial achievement gap?. International Economic Review, 54(1), 355-383.

Le, T. N., \& Johansen, S. (2011). The relationship between school multiculturalism and interpersonal violence: An exploratory study. Journal of school health, 81(11), 688695. https://doi.org/10.1111/j.1746-1561.2011.00645.x

Leff, J. M. (2014). Does Leadership Matter?: The Relationship of School Leadership to a Safe School Climate, Bullying, and Fighting in Middle School, [Doctoral dissertation, Florida Atlantic University].

Leinhardt, A. M. C., \& Willert, H. J. (2002). Involving stakeholders in resolving school $\begin{array}{llll}\text { violence. } \quad \text { Bulletin, 32-43. } & \text { 86(631), }\end{array}$ https://doi.org/10.1177/019263650208663104

Lunenburg, F., \& Irby, B. (2005). The principalship: Vision to action. Cengage Learning.

Lunenburg, F. C. (2010a). Communication: The process, barriers, and improving effectiveness. Schooling, 1(1), 1-10.

Lunenburg, F. C. (2010b). School violence in America's schools. Focus on colleges, universities, and schools, 4(1), 1-6.

Meeussen, L., Otten, S., \& Phalet, K. (2014). Managing diversity: How leaders' multiculturalism and colorblindness affect work group functioning. Group $\begin{array}{llll}\text { Processes } & \mathcal{E} & \text { Intergroup } & \text { Relations, }\end{array}$ https://doi.org/10.1177/1368430214525809

Melvin, L. (2011). How to keep good teachers and principals: practical solutions to today's classroom problems. R\&L Education.

Nooruddin, S., \& Baig, S. (2014). Student behavior management: School leader's role in the eyes of the teachers and students. International Journal of Whole Schooling, 10(2), 1

OECD. (2019a). TALIS 2018 Conceptual framework. https://read.oecdilibrary.org/education/teaching-and-learning-international-survery-talis-2018conceptual-framework 799337c2-en 
OECD. (2019b). TALIS starting strong 2018 technical report OECD publishing. http://www.oecd.org/education/school/oecd-starting-strong-teaching-and-learninginternational-survey.htm.

Penlington, C., Kington, A., \& Day, C. (2008). Leadership in improving schools: a qualitative perspective. School Leadership $\mathcal{E}$ Management, 28(1), 65-82. https://doi.org/10.1080/13632430701800086

Plaut, V., Sanchez-Burks, J., Buffardi, L., \& Stevens, F. (2007). What about me? Understanding non-minority aversion to diversity initiatives in the workplace. Unpublished manuscript, University of Georgia.

Plaut, V. C., Thomas, K. M., Hurd, K., \& Romano, C. A. (2018). Do Color Blindness and Multiculturalism Remedy or Foster Discrimination and Racism? Current Directions in Psychological Science, 27(3), 200-206. https://doi.org/10.1177/0963721418766068

Rattan, A., \& Ambady, N. (2013). Diversity ideologies and intergroup relations: An examination of colorblindness and multiculturalism. European Journal of Social Psychology, 43(1), 12-21. https://doi.org/https://doi.org/10.1002/ejsp.1892

Roebroeck, E., \& Guimond, S. (2015). Schooling, citizen-making, and anti-immigrant prejudice in France. Journal of Social and Political Psychology, 3(2), 20-42. https://doi.org/10.5964/jspp.v3i2.391

Rosenthal, L., \& Levy, S. R. (2010). The Colorblind, Multicultural, and Polycultural Ideological Approaches to Improving Intergroup Attitudes and Relations. Social Issues and Policy Review, 4(1), 215-246. https://doi.org/10.1111/j.17512409.2010.01022.x

Sears, D. O., Citrin, J., Cheleden, S. V., \& Van Laar, C. (1999). Cultural diversity and multicultural politics: Is ethnic balkanization psychologically inevitable? Russell Sage Foundation.

Smith, D. G., \& Schonfeld, N. B. (2000). The Benefits of Diversity what the Research Tells Us. About campus, 5(5), 16-23. https://doi.org/10.1177/108648220000500505

Stevens, F. G., Plaut, V. C., \& Sanchez-Burks, J. (2008). Unlocking the Benefits of Diversity: All-Inclusive Multiculturalism and Positive Organizational Change. The Journal of Applied Behavioral Science, 44(1), 116-133. https://doi.org/10.1177/0021886308314460

Stevenson, H. C., Herrero-Taylor, T., Cameron, R., \& Davis, G. Y. (2002). “Mitigating instigation": Cultural phenomenological influences of anger and fighting among "big-boned" and "baby-faced" African American youth. Journal of Youth and Adolescence, 31(6), 473-485. https://doi.org/10.1023/a:1020267221683

Taylor, D. M., Moghaddam, F. M., Gamble, I., \& Zellerer, E. (1987). Disadvantaged Group Response to Perceived Inequality: From Passive Acceptance to Collective Action. The Journal of Social Psychology, 127(3), 259-272. https://doi.org/10.1080/00224545.1987.9713692

Thomas, K. M. (2008). Diversity Resistance in Organizations. Psychology Press.

Verkuyten, M. (2005). Ethnic group identification and group evaluation among minority and majority groups: Testing the multiculturalism hypothesis. Journal of personality and social psychology, 88(1), 121. https://doi.org/10.1037/0022-3514.88.1.121 
Verkuyten, M., \& Thijs, J. (2013). Multicultural education and inter-ethnic attitudes. European Psychologist.18(3)179-190 https://doi.org/10.1027/1016-9040/a000152

Vervoort, M. H. M., Scholte, R. H. J., \& Overb eek, G. (2008). Bullying and Victimization Among Adolescents: The Role of Ethnicity and Ethnic Composition of School Class. Journal of Youth and Adolescence, 39(1), 1. https://doi.org/10.1007/s10964-0089355-y

Wang, W., Qian, Y., Wang, Y., \& Ma, Y. (2020). Violence exposure among Chinese middle school students: Characteristics and influencing factors. Children and youth services review, 113, 105000. https://doi.org/10.1016/j.childyouth.2020.105000

Wells, A. S., Fox, L., \& Cordova-Cobo, D. (2016). How racially diverse schools and classrooms can benefit all students. The Education Digest, 82(1), 17.

World Health Organization. (2002). World Report on Violence and Health https://www.refworld.org/docid/54aa8f744.html 
Onwubuya Gift Chinemerem

SCHOOL VIOLENCE IN DIVERSITY PERSPECTIVE: EVIDENCE

FROM TEACHING AND LEARNING INTERNATIONAL SURVEY 2018

\section{Appendix A}

Table 1: Descriptive Statistics

\begin{tabular}{|c|c|c|c|c|c|c|c|c|c|c|c|}
\hline & SV & PL & MP & ME & SCS & SLOC & PES & PYT & PYS & PEL & GENDER \\
\hline Mean & 1.78 & 1.22 & 1.17 & 1.23 & 1.16 & 3.022 & 1.462 & 8.90 & 6.843 & 5.611 & 1.517 \\
\hline Median & 1.74 & 1.00 & 1.15 & 1.00 & 1.00 & 3.000 & 1.000 & 8.00 & 5.000 & 6.000 & 2.000 \\
\hline Maximum & 5.00 & 2.00 & 2.00 & 2.00 & 2.00 & 5.000 & 4.000 & 50.0 & 50.00 & 7.000 & 2.000 \\
\hline Minimum & 1.00 & 1.00 & 1.00 & 1.00 & 1.00 & 1.000 & 1.000 & 0.00 & 0.000 & 1.000 & 1.000 \\
\hline Std. Dev. & 0.50 & 0.47 & 0.25 & 0.49 & 0.35 & 1.313 & 0.679 & 7.52 & 6.591 & 0.627 & 0.492 \\
\hline Skewness & 0.92 & 1.10 & 1.27 & 1.16 & 1.69 & -0.030 & 1.790 & 1.20 & 1.807 & -0.837 & -0.068 \\
\hline Kurtosis & 4.53 & 2.39 & 4.03 & 2.27 & 3.71 & 1.928 & 6.774 & 4.69 & 6.901 & 5.809 & 1.035 \\
\hline Jarque-Bera & 2209 & 2221 & 2725 & 2087 & 4253 & 444.3 & 1042 & 3366 & 1089 & 4121.5 & 1495.5 \\
\hline Probability & 0.00 & 0.00 & 0.00 & 0.00 & 0.00 & 0.000 & 0.000 & 0.00 & 0.000 & 0.000 & 0.000 \\
\hline Observations & 9247 & 9247 & 9247 & 9247 & 9247 & 9247 & 9247 & 9247 & 9247 & 9247 & 9247 \\
\hline
\end{tabular}

Note: SV = School violence, PDL = Professional development in leadership, MPP = Multicultural policies and practices, MCSE = Multicultural school environment, SCS $=$ School sector, SLOC $=$ School location, PES = Principal employment status, PYET = Principal's years of experience in total, PYECS = Principal's years of experience in current school, PEL = Principal's education level

Table 2: Correlation Matrix

\begin{tabular}{|c|c|c|c|c|c|c|c|c|c|c|c|}
\hline Variables & SV & PDL & MPP & MCE & SCS & SLOC & PES & PT & PYCS & PEL & GENDER \\
\hline SV & 1.000 & & & & & & & & & & \\
\hline \multirow[t]{2}{*}{ PDL } & -0.024 & 1.000 & & & & & & & & & \\
\hline & $(0.023)$ & & & & & & & & & & \\
\hline \multirow[t]{2}{*}{ MPP } & 0.069 & 0.076 & 1.000 & & & & & & & & \\
\hline & $(0.000)$ & $(0.000)$ & & & & & & & & & \\
\hline \multirow[t]{2}{*}{ MCE } & -0.236 & 0.018 & -0.041 & 1.000 & & & & & & & \\
\hline & $(0.000)$ & $(0.087)$ & $(0.000)$ & & & & & & & & \\
\hline \multirow[t]{2}{*}{ SCS } & -0.067 & 0.030 & 0.007 & -0.063 & 1.000 & & & & & & \\
\hline & $(0.000)$ & $(0.004)$ & $(0.492)$ & $(0.000)$ & & & & & & & \\
\hline \multirow[t]{2}{*}{ SLC } & 0.081 & -0.045 & -0.045 & -0.173 & 0.243 & 1.000 & & & & & \\
\hline & $(0.000)$ & $(0.000)$ & $(0.000)$ & $(0.000)$ & $(0.000)$ & & & & & & \\
\hline \multirow[t]{2}{*}{ PES } & -0.137 & 0.121 & -0.036 & 0.060 & 0.007 & -0.105 & 1.000 & & & & \\
\hline & $(0.000)$ & $(0.000)$ & $(0.001)$ & $(0.000)$ & $(0.527)$ & $(0.000)$ & & & & & \\
\hline
\end{tabular}


Onwubuya Gift Chinemerem

SCHOOL VIOLENCE IN DIVERSITY PERSPECTIVE: EVIDENCE

FROM TEACHING AND LEARNING INTERNATIONAL SURVEY 2018

\begin{tabular}{|c|c|c|c|c|c|c|c|c|c|c|c|}
\hline PYT & -0.080 & -0.003 & -0.040 & 0.028 & 0.030 & -0.020 & -0.028 & 1.0 & & & \\
\hline & $(0.000)$ & $(0.741)$ & $(0.000)$ & $(0.006)$ & $(0.004)$ & $(0.052)$ & (0.007) & & & & \\
\hline \multirow[t]{2}{*}{ PYECS } & -0.094 & 0.011 & -0.053 & 0.043 & 0.035 & -0.066 & 0.041 & 0.674 & 1.000 & & \\
\hline & $(0.000)$ & $(0.306)$ & $(0.000)$ & $(0.000)$ & $(0.001)$ & $(0.000)$ & $(0.000)$ & $(0.000)$ & & & \\
\hline \multirow[t]{2}{*}{ PEL } & 0.049 & -0.048 & -0.026 & -0.076 & -0.004 & 0.032 & -0.035 & 0.048 & 0.056 & 1.000 & \\
\hline & $(0.000)$ & $(0.000)$ & $(0.013)$ & $(0.000)$ & $(0.702)$ & $(0.002)$ & $(0.001)$ & $(0.000)$ & $(0.000)$ & & \\
\hline \multirow[t]{2}{*}{ GENDER } & 0.037 & 0.024 & 0.008 & 0.028 & -0.008 & -0.012 & -0.058 & 0.082 & 0.007 & -0.040 & 1.000 \\
\hline & $(0.000)$ & $(0.019)$ & $(0.431)$ & $(0.008)$ & $(0.456)$ & $(0.269)$ & $(0.000)$ & $(0.000)$ & $(0.493)$ & $(0.000)$ & \\
\hline
\end{tabular}

Note: SV = School violence, PDL = Professional development in leadership, MPP = Multicultural policies and practices, MCSE = Multicultural school environment,

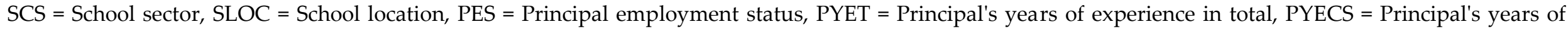
experience in current school, PEL = Principal's education level. Figures presented in parentheses are probability values.

Table 3: Country Fixed Effects Estimation for School Violence

\begin{tabular}{|c|c|c|c|c|}
\hline Variables & Coef. & Std. Err. & t-ratio & p-value \\
\hline Intercept & $1.964^{* * *}$ & 0.063 & 31.090 & 0.000 \\
\hline PDL & -0.002 & 0.011 & -0.220 & 0.827 \\
\hline MPP & $0.046^{* *}$ & 0.021 & 2.160 & 0.031 \\
\hline MCSE & $-0.121^{* * *}$ & 0.012 & -10.450 & 0.000 \\
\hline SCS & $-0.271^{* * *}$ & 0.014 & -19.740 & 0.000 \\
\hline SLOC & $0.047^{* * *}$ & 0.004 & 11.710 & 0.000 \\
\hline PES & $-0.020^{* *}$ & 0.008 & -2.440 & 0.015 \\
\hline PYET & $-0.001^{*}$ & 0.001 & -1.680 & 0.094 \\
\hline PYECS & $-0.004^{* * *}$ & 0.001 & -4.450 & 0.000 \\
\hline PEL & $0.023^{* * *}$ & 0.009 & 2.730 & 0.006 \\
\hline GENDER & $0.026^{* * *}$ & 0.010 & 2.670 & 0.008 \\
\hline Country Fixed Effects & Yes & & & \\
\hline \multicolumn{5}{|l|}{ Observations } \\
\hline Principals & 9,247 & & & \\
\hline Countries & 47 & & & \\
\hline
\end{tabular}

Note: $\mathrm{PDL}=$ Professional development in leadership, MPP $=$ Multicultural policies and practices, MCSE $=$ Multicultural school environment, $\mathrm{SCS}=\mathrm{School}$ sector, SLOC $=$ School location, PES $=$ Principal employment status, PYET $=$ Principal's years of experience in total, PYECS $=$ Principal's years of experience in current school, PEL $=$ Principal's education level. ${ }^{* * * * * * *}$ denotes statistical significance of $10 \%, 5 \%$ and $1 \%$ respectively. 


\section{Appendix B}

\section{Table 3: Description of Variables}

\begin{tabular}{|c|c|}
\hline Variable name & Description \\
\hline $\begin{array}{l}\text { Dependent variable } \\
\text { School violence }\end{array}$ & $\begin{array}{l}\text { Composite variable using seven items of five Likert scale (from } 1 \text { to 5, never, less than monthly. Monthly weekly, and daily). How } \\
\text { often the following does occur a) vandalism and theft. b) Intimating or bullying among students (or order forms of verbal abuse). c) } \\
\text { Physical injuries caused by violence among students. (d) Intimidation of verbal abuse of teachers or staff. e) Use or possession of } \\
\text { drugs and/or alcohol. f) A student or parent/ guardian reports hurtful information on the internet about students e.g., a student or } \\
\text { parent guardian reports unwanted electronic contact among students (e.g. texts, e-mails, online). }\end{array}$ \\
\hline $\begin{array}{l}\text { Main independent } \\
\text { variable } \\
\text { Professional development } \\
\text { in leadership }\end{array}$ & $\begin{array}{l}\text { The binary variable of } 0=\text { no and } 1=\text { yes indicating whether the school principal has participated in leadership training in less than } \\
12 \text { months. }\end{array}$ \\
\hline $\begin{array}{l}\text { Other variables } \\
\text { Multicultural practices } \\
\text { and policies }\end{array}$ & $\begin{array}{l}\text { 1. Composite variable using a binary item of policies and practice in multicultural education. } \\
\text { In this school, are the following policies and practices in relation to diversity implemented? } \\
\text { a) Supporting activities or organizations that encourage students' expression of diverse ethnic and cultural identities (e.g. artistic } \\
\text { groups). b) Organizing multicultural events (e.g. cultural diversity day. c) Teaching students how to deal with ethnic and cultural } \\
\text { discrimination. d) Adopting teaching and learning practices that integrate global issues throughout the curriculum. } \\
\text { In this school, are the following policies and practices implemented? } \\
\text { a) Teaching students to be inclusive of different socio-economic backgrounds. b) Explicit policies against gender discrimination. c) } \\
\text { Explicit policies against socio-economic discrimination. d) Additional support for students from disadvantaged backgrounds. } \\
\text { 2. Binary item of multicultural background. } \\
\text { Does this School include students of more than one cultural or ethnic background? }\end{array}$ \\
\hline \multicolumn{2}{|r|}{ e } \\
\hline Gender & Binary variable, $0=$ male, $1=$ female. \\
\hline Educational background & $\begin{array}{l}\text { (From } 1 \text { to } 7 \text {, as Below <ISCED } 2011 \text { Level 3>, <ISCED } 2011 \text { Level 3>, <ISCED } 2011 \text { Level 4>, <ISCED } 2011 \text { Level 5>, <ISCED } 2011 \text { Level } \\
\text { 6>, <ISCED } 2011 \text { Level 7>, <ISCED } 2011 \text { Level 8>). }\end{array}$ \\
\hline Experience as a principal & Principal's years of experience in total, and Principal's years of experience in the current school. \\
\hline School location & Binary variable, $0=$ rural or town $(\leq 100,000$ people $), 1=$ city $(>100,000$ people $)$ \\
\hline Employment status & Binary variable, 0 = part-time, 1 = full time. \\
\hline
\end{tabular}



will be applied to their work. Under the terms of this license, no permission is required from the author(s) or publisher for members of the community to copy, distribute, transmit or adapt the article content, providing a proper, prominent and unambiguous attribution to the authors in a manner that makes clear that the materials are being reused under permission of a Creative Commons License. Views, opinions and conclusions expressed in this research article are views, opinions and conclusions of the author(s). Open Access Publishing Group and European Journal of Education Studies shall not be responsible or answerable for any loss, damage or liability caused in relation to/arising out of conflicts of interest, copyright violations and inappropriate or inaccurate use of any kind content related or integrated into the research work. All the published works are meeting the Open Access Publishing requirements and can be freely accessed, shared, modified, distributed and used in educational, commercial and non-commercial purposes under a Creative Commons Attribution 4.0 International License (CC BY 4.0). 